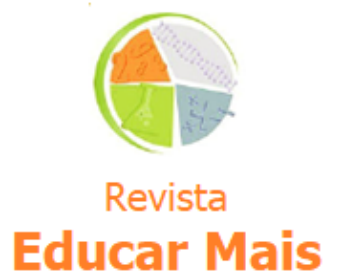

\title{
Stuart Hall: cultura, identidade e representação
}

\author{
Stuart Hall: Culture, Identity and Representation
}

Maria Laura Brenner Moraes ${ }^{1}$

\section{RESUMO}

Este trabalho apresenta o resumo de algumas ideias de Stuart Hall sobre cultura, identidade e representação. Os estudos de Stuart Hall salientam o grau de importância assumido pela cultura na interpretação da realidade e dos comportamentos, assim como as formas pelas quais a mesma é utilizada para transformar a nossa compreensão, explicação e modelos teóricos acerca do mundo no qual vivemos. Do mesmo modo, este texto traz o conceito de representação, proposto pelo autor como ferramenta teórica, a partir da análise de três teorias que discutem a representação: a reflexiva, a intencional e a construcionista, demonstrando que os atores sociais por meio de seus sistemas de conceituação oferecem os sentidos.

Palavras-chave: Estudos Culturais; cultura; identidade; representação.

\begin{abstract}
This work presents a summary of some of Stuart Hall's ideas on culture, identity, and representation. Stuart Hall's studies emphasize the importance of culture in interpreting reality and behaviors as well as the ways in which it is used to transform our understanding, explanation, and theoretical models about the world in which we live. In the same way, this text brings the concept of representation, proposed by the author as a theoretical tool, from the analysis of three theories that discuss representation: the reflexive, the intentional and the constructional, demonstrating that the social actors through their systems of conceptualization offer the senses.
\end{abstract}

Keywords: Cultural Studies; culture; identity; representation.

\section{INTRODUÇÃO}

A contribuição de Stuart Hall no campo dos Estudos Culturais é considerada de importância fundamental, imprimindo sua marca no rumo teórico e político que o campo foi assumindo a partir dos anos 70 (ESCOSTEGUY, 2003). Nesse sentido, acredita-se ser significativo tratar-se de como a cultura por meio de suas diferentes manifestações e instrumentos tem produzido novas subjetividades e novas formas de ser, estar e entender o mundo, uma vez que os modos de ser não se engendram mais predominantemente a partir de instituições específicas, mas a partir de dispositivos sutis, indiretos e plurais, dispersos no tecido social, pelos quais nos subjetivam sem que nos apercebamos da sua atuação. São valiosas, portanto, as articulações entre cultura, discurso e produção subjetiva,

\footnotetext{
${ }^{1}$ IFSul - Instituto Federal de Educação, Ciência e Tecnologia do Sul-rio-grandense, Pelotas/RS - Brasil.
} 
desenvolvidas no campo dos Estudos Culturais, sendo a cultura entendida como prática de significação e o mundo social concebido como construído discursivamente.

Muito embora os trabalhos dos Estudos Culturais, não sejam unívocos em suas perspectivas de problematização, unem-se por uma abordagem cuja ênfase recai sobre a importância de se analisar o conjunto da produção cultural e de práticas de uma sociedade que carregam e produzem significados, para entender os padrões de comportamento e o conjunto de idéias compartilhadas por homens e mulheres que nela vivem. Para Stuart Hall, considerado um dos mais conhecidos analistas contemporâneos da cultura, os Estudos Culturais se constituíram como um projeto político de oposição, e suas manifestações sempre foram acompanhadas de transtorno, discussão, ansiedades instáveis e um silêncio inquietante.

\section{CULTURA, IDENTIDADE E REPRESENTAÇÃO}

Ao questionar-se sobre a centralidade da cultura, Stuart Hall (1997), além de destacar o seu grau de importância na interpretação da realidade e dos comportamentos, reconhece a enorme expansão de tudo que a ela está associado, desde a segunda metade do século $\mathrm{XX}$, assim como o seu papel constitutivo em todos os aspectos da vida social, na constituição da subjetividade, da própria identidade, e da pessoa como um ator social.

Conforme Hall,

[...] a ação social é significativa tanto para aqueles que a praticam quanto para os que a observam: não em si mesma mas em razão dos muitos e variados sistemas de significado que os seres humanos utilizam para definir o que significam as coisas e para codificar, organizar e regular sua conduta uns em relação aos outros (HALL, 1997, p. 16).

A centralidade da cultura, ressaltada por Stuart Hall têm uma dimensão epistemológica, que vem sendo denominada "virada cultural", no sentido substantivo, empírico e material da palavra (HALL, 1997, p. 17), referindo-se a esse poder instituidor de que são dotados os discursos circulantes no circuito da cultura, que transformando nossa compreensão, explicação e modelos teóricos do mundo (HALL, 1997). Desde o entendimento de que os discursos constituem-se como redes de significações, Hall considera que os mesmos são tomados pelos sujeitos para se auto interpretar e acabam por produzi-los. A interpelação acontece quando o sujeito se reconhece a partir dos discursos. Ele os toma como algo que Ihe diz respeito, identifica-se e produz-se como um sujeito daquele modo, compreende e explica a si e ao mundo a partir daquele regime de verdade.

Para Hall é justamente na esfera cultural que se dá a luta pela significação, portanto, os textos culturais são o próprio local onde o significado é negociado e fixado e, as lutas pelo poder passam cada vez mais a serem extremamente simbólicas. A cultura, portanto, na perspectiva de Hall é um dos elementos mais dinâmicos e mais imprevisíveis da mudança histórica do novo milênio. Em suas palavras

[...] não devemos nos surpreender, então, que as lutas pelo poder deixem de ter uma forma simplesmente física e compulsiva para serem cada vez mais simbólicas e discursivas, e que o poder em si assuma, progressivamente, a forma de uma política cultural (HALL, 1997, p. 20). 
Na avaliação do autor, a cutura tem assumido uma importância sem precedentes no que diz respeito à estrutura e à organização da sociedade moderna tardia, sendo constitutiva em toda análise social (HALL, 1997).

A origem das reflexões de Hall sobre o funcionamento da linguagem como processo de significação encontra-se em sua concepção de cultura como um conjunto de significados partilhados (HALL, 1997). Conforme Hall (2002), se a linguagem atribui sentido, os significados só podem ser partilhados pelo acesso comum à linguagem, que funciona como sistema de representação. Desse modo, a representação através da linguagem é central para os processos pelos quais é produzido o significado.

Conforme Hall (2002) é através do uso que fazemos das coisas, o que dizemos, pensamos e sentimos - como representamos - que damos significado. Em parte damos significados aos objetos, pessoas e eventos através da estrutura de interpretação que trazemos. Em parte, damos significado através da forma como as utilizamos, ou as integramos em nossas práticas cotidianas.

A análise de Hall sobre o conceito de representação é motivada pela investigação sobre a forma como se constrói o significado. De acordo com o autor, os significados culturais têm efeitos reais e regulam práticas sociais. O reconhecimento do significado faz parte do senso de nossa própria identidade, através da sensação de pertencimento. Os sinais possuem significado compartilhado, significando nossos conceitos, ideias e sentimentos de forma que outros decodifiquem ou interpretem mais ou menos de igual forma. Portanto, as linguagens funcionam através da representação, constituindo-se em sistemas de representação. Essa é uma visão atrelada à "virada cultural" nas ciências sociais e humanas, relacionada a uma abordagem socioconstrucionista, onde a representação é concebida como importante para a própria constituição das coisas.

Em seus escritos, Hall (2002, p. 9-10) aborda três teorias que discutem a representação: a reflexiva, a intencional e a construcionista. Cada uma delas apresenta abordagens diferenciadas para a interpretação dos significados nas mensagens. Na teoria reflexiva, a linguagem funciona como espelho que reflete o verdadeiro significado já existente no mundo; na intencional, aquele que fala impõe o significado através da linguagem; e, na teoria construcionista, a linguagem é tomada como um produto social, no qual os significados são construídos através dos sistemas de representação. É nessa terceira visão que o autor encontra um melhor ajuste à sua concepção da representação.

Em poucas décadas o mundo mudou. As sociedades tornaram-se mais complexas e tecnológicas, exigindo novas formas de pensar, de estar e de conviver. Os meios de produção, circulação e troca cultural, em particular, têm se expandido, através das tecnologias e da revolução da informação. E, como se pode constatar, inegavelmente as análises da contemporaneidade que a tem caracterizado como marcada pela flexibilidade e pelo dinamismo, dificilmente deixam de apontar o boom das tecnologias da comunicação e a centralidade que os produtos midiáticos adquiriram em nosso tempo. A mídia tem oferecido, predominantemente, representações hegemônicas para problematizar a questão das diferenças e para determinar que certos modelos de ser, sejam produzidos e circulem socialmente, sustentando o marketing de produtos e ideias (HALL, 1997).

As revoluções da cultura causam impacto sobre os modos de viver, sobre o sentido que as pessoas dão à vida, sobre suas aspirações para o futuro. E, nesse contexto, a representação assume centralidade, uma vez que seu significado encontra-se no fato de "[...] usar a linguagem para dizer algo com sentido sobre, ou para representar de maneira significativa o mundo a outras pessoas" 
(2002, p.2). Além disso, as representações têm sérias implicações sobre as identidades, pois as mesmas têm a ver como temos sido representados e como essa representação afeta a forma como nós podemos representar, surgindo das próprias narrativas do eu (HALL, 2000, p.109).

Atualmente, a identidade é um conceito bastante discutido pelas teorias sociais, as quais procuram demonstrar, basicamente, que as velhas identidades, responsáveis pela estabilidade do mundo social, estão entrando em declínio e sendo substituídas pelas novas identidades, caracterizadas, entre outras coisas, pela fragmentação do indivíduo moderno, fato que, segundo o autor, tem promovido grande mudança estrutural nas sociedades.

Conforme Hall, a assim chamada "crise de identidade" é vista como parte de um processo mais amplo de mudança, que está deslocando as estruturas e processos centrais das sociedades modernas e abalando os quadros de referência que davam aos indivíduos uma ancoragem estável no mundo social" (HALL, 2006, p. 7).

[...] O que denominamos "nossas identidades" poderia provavelmente ser melhor conceituado como as sedimentações através do tempo daquelas diferentes identificações ou posições que adotamos e procuramos "viver", como se viessem de dentro, mas que, sem dúvida, são ocasionadas por um conjunto especial de circunstâncias, sentimentos, histórias e experiências única e peculiarmente nossas, como sujeitos individuais. Nossas identidades são, em resumo, formadas culturalmente (HALL, 2000).

Hall utiliza o termo identidade para significar

[...] o ponto de encontro, o ponto de sutura, entre, por um lado, os discursos e as práticas que tentam nos 'interpelar', nos falar ou nos convocar para que assumamos nossos lugares como os sujeitos sociais de discursos particulares e, por outro lado, os processos que produzem subjetividades que nos constroem como sujeitos aos quais se pode 'falar'"(HALL, 2000, p.111-112).

Desse modo, entende-se que todas as fronteiras da identidade não são fixas, estão sempre sendo reconstruídas, sem nunca poder-se afirmar que compõe-se de um tecido por inteiro, mas sim, um conjunto de retalhos superpostos.

Para o autor, as identidades sociais devem ser pensadas como construídas no interior da representação, através da cultura, sendo resultantes de um processo de identificação que nos permite posicionarmo-nos no interior das definições fornecidas pelos discursos culturais. Desse modo, nossas subjetividades são produzidas parcialmente de modo discursivo e dialógico. De igual forma, Hall ao desenvolver uma concepção de identidade como estratégica e posicional defende que, na modernidade tardia, as identidades são cada vez mais fragmentadas e fraturadas, multiplicadamente construídas ao longo de discursos, práticas e posições. Nessa perspectiva, a identidade emerge do diálogo entre os conceitos e definições representados para nós pelos discursos de uma cultura e pelo nosso desejo de responder aos apelos feitos por estes significados (HALL, 2000).

Frente a isso, o autor propõe três concepções de identidade: a do sujeito do Iluminismo, baseado no indivíduo totalmente centrado, unificado e dotado da razão; a do sujeito sociológico, baseada na ideia de que o núcleo interior do sujeito não é autônomo e autossuficiente, mas formado na relação com outras pessoas e, a do sujeito pós-moderno, resultante de mudanças estruturais e institucionais que torna o processo de identificação instável e provisório, tornando a identidade pouco fixa e 
permanente: "[...o sujeito assume identidades diferentes em diferentes momentos, identidades que não são unificadas ao redor de um 'eu' coerente" (HALL, 2006, p. 10-13).

Segundo Stuart Hall, esse processo está intimamente relacionado ao caráter da mudança na modernidade tardia, sobretudo aquela que se conhece pelo nome de globalização, fenômeno relacionado à própria essência da sociedade, uma vez que ela não é um todo unificado e bem delimitado, sendo constantemente descentrada ou deslocada por forças que lhe são exteriores.

Nesse sentido, Stuart Hall apresenta as principais mudanças ocorridas no sujeito e na identidade modernos, já que, antes da era moderna, o indivíduo encontrava sua identidade ancorada em apoios estáveis (tradições, estruturas), o que deixa de acontecer com a modernidade, emergindo então uma concepção mais social do sujeito. Na modernidade tardia, a concepção de identidade passa por transformações substanciais: o sujeito passa por um profundo processo de descentramento, que tem origem, por exemplo, nas teorias revolucionárias de Marx, Freud, Saussure, Foucault e outros. Acrescenta ainda o autor, que não são apenas as identidades individuais que passam, na modernidade tardia, por um processo de transformação, o mesmo ocorrendo, por exemplo, com as identidades culturais/nacionais, igualmente deslocadas pela globalização.

"[...]as culturas nacionais são compostas não apenas de instituições culturais, mas também de símbolos e representações. Uma cultura nacional é um discurso - um modo de construir sentidos que influencia e organiza tanto nossas ações quanto a concepção que temos de nós mesmos" (HALL, 2006, p. 50).

Embora possam ser representadas como unificadas, as identidades nacionais são marcadas pelas diferenças, e é exatamente essa característica da identidade cultural/nacional que a contemporaneidade traz à tona: não podendo ser organizadas nem sob o conceito aparentemente homogêneo de etnia, nem de raça, conclui-se que "as nações modernas são, todas, híbridos culturais" (HALL, 2006, p. 62)

Com o fenômeno da globalização, e suas consequências imediatas - compressão espaço-temporal, aceleração dos processos globais, encurtamento das distâncias —, as identidades culturais/nacionais sofrem um processo de deslocamento e fragmentação. Nas palavras de Hall,

" [...] quanto mais a vida se torna mediada pelo mercado global de estilos, lugares e
imagens, pelas viagens internacionais, pelas imagens da mídia e pelos sistemas de
comunicação globalmente interligados, mais as identidades se tornam desvinculadas
- desalojadas - de tempos, lugares, histórias e tradições específicos e parecem
'flutuar livremente'. Somos confrontados por uma gama de diferentes identidades
(cada qual nos fazendo apelos, ou melhor, fazendo apelos a diferentes partes de nós),
dentre as quais parece possível fazer uma escolha. (HALL, 2006, p. 75)

Evidentemente, todo esse processo não surge sem que haja uma contrapartida, isto é, aquelas tendências que argumentam a favor da homogeneização cultural, portanto contrários à pretensa fragmentação global. Tais tendências afirmam, por exemplo, que existiria ainda uma preocupação com a diferença, portanto, com o local; ou que a globalização não atingiria todas as regiões da mesma maneira e na mesma proporção, sendo, portanto, desigual; ou que a globalização seria um fenômeno essencialmente ocidental.

De qualquer maneira, embora seu efeito geral seja contraditório, a globalização acaba tendo, sim, um efeito de contestar e deslocar as identidades centradas, fechadas numa cultura nacional, exercendo uma influência pluralizante sobre as identidades, tornando-as, portanto, mais diversas. 


\section{REFERÊNCIAS}

ESCOSTEGUY, Ana Carolina. Stuart Hall: esboço de um itinerário biointelectual. In: Revista FAMECOS. Porto Alegre. N.21, agosto 2003. P. 61-74.

HALL, Stuart. A centralidade da cultura: notas sobre as revoluções culturais do nosso tempo. In: Educação \& Realidade. jul/dez. 1997. p. 15-46.

A identidade cultural na pós-modernidade. 11 ed. Rio de Janeiro: DP\&A, 2006.

El trabajo de la representación. IEP - Instituto de Estudios Peruanos: Lima, Maio, 2002.

Quem precisa de identidade? In: SILVA, Tomaz Tadeu da (org.). Identidade e diferença: a perspectiva dos Estudos Culturais. Petrópolis,RJ: Vozes, 2000.. 